\title{
miR-21/PTEN pathway mediates the cardioprotection of geniposide against oxidized low-density lipoprotein-induced endothelial injury via suppressing oxidative stress and inflammatory response
}

\author{
SONG ZHOU, YUNJING SUN, KAI ZHAO, YANZHOU GAO, JIANGMAN CUI, LIPING QI and LINGFANG HUANG
}

Department of Cardiology, The Third Hospital of Xingtai City, Xingtai, Hebei 054000, P.R. China

Received May 2, 2019; Accepted November 21, 2019

DOI: $10.3892 / \mathrm{ijmm} .2020 .4520$

\begin{abstract}
Oxidized low-density lipoprotein (ox-LDL)-induced vascular endothelial damage, oxidative stress and inflammation play a vital role in the pathophysiology of atherosclerosis. Geniposide is the primary active ingredient from Gardenia jasminoides Ellis associated with anti-oxidative properties and cardioprotective action. However, the therapeutic mechanism of geniposide in atherosclerosis remains unclear. Hence, the present study aimed to elucidate the underlying mechanisms of geniposide in oxidative stress and inflammatory response during ox-LDL injury in human umbilical vein endothelial cells (HUVECs), focusing particularly on the microRNA (miR)-21/PTEN pathway. The results demonstrated that geniposide pretreatment significantly increased cell viability, decreased lactate dehydrogenase release, increased miR-21 level and decreased PTEN expression under ox-LDL condition. Subsequently, transfection with miR-21 mimic enhanced the protection of geniposide on ox-LDL-induced cytotoxicity and apoptosis (mediated by the upregulation of apoptotic rate and caspase- 3 activity), whereas miR-21 inhibitor reversed these effects of geniposide. In addition, geniposide resulted in an anti-oxidant effect as evidenced by the decrease in reactive oxygen species generation, malondialdehyde content and NADPH oxidase 2 expression, and the increase in superoxide dismutase, glutathione peroxidase and catalase activities in ox-LDL-treated HUVECs, which were exacerbated by miR-21 mimic and reversed by miR-21 inhibitor. Furthermore, geniposide mitigated the ox-LDL-induced inflammatory response, demonstrated by a downregulation of pro-inflammatory cytokine (IL- $1 \beta$, IL-6, and TNF- $\alpha$ ) levels and an upregulation of anti-inflammatory cytokine (IL-10)
\end{abstract}

Correspondence to: Professor Song Zhou, Department of Cardiology, The Third Hospital of Xingtai City, 108 Gangtie Road, Qiaoxi, Xingtai, Hebei 054000, P.R. China

E-mail: zhousong0102@126.com

Key words: geniposide, atherosclerosis, microRNA-21/PTEN pathway, oxidative stress, inflammations level. However, miR-21 mimic enhanced, whereas miR-21 inhibitor attenuated, these effects of geniposide. In conclusion, the present results indicated that geniposide protects HUVECs from ox-LDL injury by inhibiting oxidative stress and inflammation, and that these effects are partly due to the enhancement of the miR-21/PTEN pathway.

\section{Introduction}

Atherosclerosis is a chronic multifactorial vessel disease, promoted by several risk factors, and is the main cause of cardiovascular disease, which is a primary cause of mortality worldwide, accounting for $\sim 18$ million mortalities per year ( $\sim 31 \%$ of all mortalities) $(1,2)$. It is well understood that endothelial cells (ECs), macrophages and smooth muscle cells are all involved in atherosclerosis (3). The process of endothelial injury and its dysfunction serves vital roles in the development of atherosclerosis and deserves more attention (4). Endothelial cell dysfunction, which manifests in lesion-prone areas of the arterial vasculature, occurs throughout the early stages of atherosclerosis and serves a role in plaque regression and plaque instability (5). Increasing evidence has demonstrated that multiple pathways and physiopathological processes are also involved in the development of atherosclerosis, such as inflammation, apoptosis, lipid deposition, foam cell formation, oxidative stress and necrosis (6-8). Oxidized low-density lipoprotein (ox-LDL) can destroy endothelial function and enhance endothelial apoptosis, leading to endothelial injury, thus contributing to the development and pathogenesis of atherosclerosis (9). Oxidative stress and inflammation interact to promote vascular wall LDL oxidation, resulting in a high level of ox-LDL, which leads to apoptosis of vascular endothelial cells and subsequent endothelial injury $(7,9)$. Human umbilical vein endothelial cells (HUVECs) are among one of the most popular models used for ECs in vitro because human umbilical veins are relatively more available compared with other types of blood vessels (10). Therefore, interventions for endothelial injury and oxidative stress induced by ox-LDL may be utilized as effective novel therapeutic strategies for the treatment of atherosclerosis.

Geniposide, a major compound extracted from the gardenia fruit, is a type of traditional Chinese medicine for the treatment 
of inflammation, brain disorders and hepatic disease (11). Geniposide exhibits a broad spectrum of pharmacological actions involving anti-apoptosis (12), anti-inflammatory injury (13), anti-oxidative stress (14), anti-cancer (15) and anti-angiogenesiseffects(16).Previousinvitroandinvivo studies have focused on the potential cardioprotective effects of geniposide, particularly in atherosclerosis (17-19). Cheng et al (17) demonstrated that geniposide can decrease plaque size and mitigate atherosclerosis-associated inflammatory damage by regulating the miR-101-associated signaling pathway. Another study also demonstrated that the combination of Scutellaria baicalensis georgi with geniposide exerts inflammation-regulatory effects and inhibits atherosclerotic lesions (19). However, the mechanisms underlying the protective effects of geniposide on anti-oxidative stress and anti-inflammatory response in atherosclerosis are poorly understood.

MicroRNAs (miRNAs/miRs), endogenous short non-coding RNAs, $\sim 22$ nucleotides in length, are well established as the mediators of post-transcriptional regulation in a wide array of biological processes (20). Among them, miR-21, one of the major dynamically modulated miRNAs, elicits various pathophysiological processes implicated in the development of various diseases, such as neurodegenerative diseases and cancer, and serves vital roles in cardiovascular diseases (21-23). Previous studies have confirmed that miR-21 in endothelial cells is significantly increased in atherosclerotic plaques and that it causes pharmacological effects by directly targeting the PTEN tumor suppressor gene, indicating a pivotal effect of the miR-21/PTEN pathway in atherosclerosis $(24,25)$. A number of reports have indicated that the miR-21/PTEN pathway regulates important functions of ECs, apoptosis and inflammatory responses during atherosclerosis $(26,27)$. However, the exact actions of the miR-21/PTEN pathway in the progression of atherosclerosis and in the cardioprotection of geniposide remain unknown.

Hence, the present study aimed to investigate whether the miR-21/PTEN pathway contributes to the antioxidant and anti-inflammatory actions of geniposide in ox-LDL injury in HUVECs. Overall, the present study provided crucial evidence that geniposide may be an active component in preventing the progression of atherosclerosis.

\section{Materials and methods}

Cell culture and treatment. HUVECs were supplied by the American Type Culture Collection and cultured in DMEM (Gibco; Thermo Fisher Scientific, Inc.) supplemented with $10 \%$ (v/v) fetal bovine serum (Thermo Fisher Scientific, Inc.) and $100 \mu \mathrm{g} / \mathrm{ml}$ penicillin/streptomycin (Beyotime Institute of Biotechnology) in a humidified atmosphere with $5 \% \mathrm{CO}_{2}$ at $37^{\circ} \mathrm{C}$. HUVECs were incubated with ox-LDL (25, 50 or $100 \mu \mathrm{g} / \mathrm{ml}$; Beijing Solarbio Life Science Company; cat. no. H7950; dissolved in culture medium) for $24 \mathrm{~h}$ at $37^{\circ} \mathrm{C}$ to establish an in vitro atherosclerotic cell model. The control group was treated with same amount of culture medium instead of ox-LDL.

To illustrate the physiological effect of geniposide on ox-LDL injury, HUVECs were pretreated with different concentrations of geniposide $(5,10,20,40$ or $80 \mu \mathrm{M}$; Shanghai Pureone Biotechnology; purity $>98 \%$; cat. no. P0118) for
$30 \mathrm{~min}$ and then treated with ox-LDL $(50 \mu \mathrm{g} / \mathrm{ml})$ for $24 \mathrm{~h}$ at $37^{\circ} \mathrm{C}$. To demonstrate the role of the miR-21/PTEN pathway in the cardioprotection of geniposide during atherosclerosis, HUVECs were transfected with miR-21 mimic, miR-21 inhibitor or miRNA negative control (miR-NC) and then treated with geniposide $(40 \mu \mathrm{M})$ for $1 \mathrm{~h}$ followed by ox-LDL $(50 \mu \mathrm{g} / \mathrm{ml})$ for $24 \mathrm{~h}$ at $37^{\circ} \mathrm{C}$.

Transfection. In order to inhibit or enhance miR-21 level, miR-21 mimic (100 nM), miR-21 inhibitor (100 nM) or miRNA NC (100 nM) (Guangzhou RiboBio Co., Ltd.) were transfected into HUVECs using Lipofectamine ${ }^{\circledR} 3000$ reagent (Invitrogen; Thermo Fisher Scientific, Inc.), according to the manufacturer's protocol. The sequences were as follows: miR-21 mimic sense, 5'-UAGCUUAUCAGACUGAUGUUGA-3'; miR-21 mimic anti-sense, 5'-AACAUCAGUCUGAUAAGCUAUU-3'; miR-21 inhibitor, 5'-UCA ACAUCAGUCUGAUAAGCUA-3'; and miR-21 negative control (miR-NC) sense, 5'-UUCUCCGAA CGUGUCACGUTT-3' and anti-sense, 5'-ACGUGACACGUU CGGAGAATT-3'. Following transfection for 6 h, the medium was changed and HUVECs were subjected to treatment with ox-LDL $(50 \mu \mathrm{g} / \mathrm{ml})$ for a further $24 \mathrm{~h}$ at $37^{\circ} \mathrm{C}$ and the cells were cultured for $48 \mathrm{~h}$. Transfection efficiency was determined using reverse transcription-quantitative PCR (RT-qPCR).

Cell viability assay. The cell viability of HUVECs was measured using a MTT assay kit (Beyotime Institute of Biotechnology; cat. no. ST316). Briefly, HUVECs were seeded onto 96 -well plates at a density of $1 \times 10^{4} /$ well. Following treatment as aforementioned, MTT solution $(5 \mathrm{mg} / \mathrm{ml}, 20 \mu \mathrm{l})$ was added to each well. Subsequently, cells were incubated for a further $4 \mathrm{~h}$ at $37^{\circ} \mathrm{C}$, and $150 \mu 1 \mathrm{DMSO}$ was added to dissolve the precipitate. The optical density (OD) at $570 \mathrm{~nm}$ was measured using a microplate reader.

Lactate dehydrogenase $(\mathrm{LDH})$ release assay. The $\mathrm{LDH}$ release from cell to supernatant was determined using a LDH Cytotoxicity assay kit (Beyotime Institute of Biotechnology; cat. no. C0016), according to the manufacturer's protocol. Briefly, following the aforementioned treatments, the supernatants were collected and centrifuged at $500 \mathrm{xg}$ for $5 \mathrm{~min}$ at room temperature to measure $\mathrm{LDH}$ release. The $\mathrm{OD}$ value was measured at $490 \mathrm{~nm}$ using a microplate reader.

Flow cytometry analysis. Apoptosis in treated HUVECs was detected using an Annexin V-fluorescein isothiocyanate (FITC)/propidium iodide (PI) apoptosis detection kits (BD Biosciences; cat. no. BD 556547), following the manufacturer's protocol. In brief, HUVECs were treated as aforementioned, and the culture medium and the cells were collected. Following two PBS washes, the cells were resuspended in $1 \mathrm{X}$ binding buffer $(100 \mu \mathrm{l})$ at a density of $1 \times 10^{5}$ cells $/ \mathrm{ml}$, and then double stained with $5 \mu 1$ Annexin V-FITC and $5 \mu 1$ PI for $15 \mathrm{~min}$ in the dark. The percentage of apoptotic cells was determined using a FACScan flow cytometer and analyzed using FCS Express software (version 1.2; BD Biosciences). Each experiment was performed in triplicate.

Mitochondrial membrane potential (MMP) determination. The MMP in HUVECs cells was detected using a 
5,5',6,6'-Tetrachloro-1,1',3,3'-tetraethylbenzimidazolylcarbocyanine iodide (JC-1) staining kit (Beyotime Institute of Biotechnology; cat. no. C2006). The cells were harvested, washed twice with PBS and resuspended in $10 \mu \mathrm{M}$ JC-1 solution at $37^{\circ} \mathrm{C}$ for $20 \mathrm{~min}$. Next, the $\mathrm{JC}-1$ staining solution was removed and the cells were washed and resuspended in PBS. The fluorescence values were then analyzed with a FACSCanto flow cytometer and FCS Express software (version 1.2, BD Biosciences). The loss of MMP was reflected by the decrease in red fluorescence from the JC-1 aggregates and the increase in green fluorescence from the JC-1 monomers.

Caspase-3 activation analysis. The caspase-3 activity in HUVECs was analyzed using a caspase-3 assay kit (Sigma-Aldrich; Merck KGaA; cat. no. CASP3F). Briefly, cells were seeded onto 6 -well plates at a density of $1 \times 10^{5}$ cells/well, treated as aforementioned, trypsinized and analyzed for $10 \mathrm{~min}$ on ice. Next, the cells lysates were mixed with caspase-3 substrate (DEVD-AFC; $1 \mu \mathrm{M}$ ) and detection buffer at $37^{\circ} \mathrm{C}$ for $2 \mathrm{~h}$. The relative fluorescence intensity of each well was detected using a microplate reader at wavelengths of $400 \mathrm{~nm}$ excitation and $505 \mathrm{~nm}$ emission.

Intracellular reactive oxygen species $(R O S)$ production determination. The intracellular ROS generation was analyzed by 2',7'-dichlorofluorescindiacetate (DCFH-DA; Beyotime Institute of Biotechnology), a ROS-sensitive fluorescent dye, followed by flow cytometry. Briefly, following relevant treatment or transfection, cells were treated with RIPA lysis buffer and washed with cold PBS twice. Next, cells were stained with $10 \mu \mathrm{M}$ 2,7-dichlorodihydrofluorescein diacetate (DCFH-DA) in the dark for $20 \mathrm{~min}$ at $37^{\circ} \mathrm{C}$, and the fluorescence intensity was detected using a FACSCalibur flow cytometer $(488 \mathrm{~nm}$ excitation/521 nm emission) and analyzed with FCS Express software (version 1.2; BD Biosciences).

Oxidative stress markers detection. HUVECs were seeded onto 6 -well plates with $1 \times 10^{6}$ cells/well. Following pretreatment as aforementioned, cells were lysed with RIPA lysis buffer (Beyotime Institute of Biotechnology). Following centrifugation at $4^{\circ} \mathrm{C}, 12,000 \mathrm{x}$ g for $10 \mathrm{~min}$, protein concentration was assayed using a BCA Protein assay kit (Beyotime Institute of Biotechnology). Malondialdehyde (MDA) content was determined using a MDA assay kit (Beyotime Institute of Biotechnology; cat. no. S0131) in accordance with the manufacturer's protocol. The enzymatic activities of superoxide dismutase (SOD), glutathione peroxidase (GSH-PX) and catalase (CAT) were determined using a Superoxide Dismutase assay kit (Nanjing Jiancheng Bioengineering Institute; cat. no. A001-2), Cellular Glutathione Peroxidase assay kit (Beyotime Institute of Biotechnology; cat. no. S0056), and Catalase assay kit (Beyotime Institute of Biotechnology; cat. no. A007-1), respectively.

$R T-q P C R$. Total RNA from treated HUVECs was extracted using TRIzol reagent (Invitrogen; Thermo Fisher Scientific, Inc.). For measuring the expression of miR-21, the first strand of complementary DNA (cDNA) was synthesized using PrimeScript Reverse Transcriptase (Takara Bio, Inc.) at $30^{\circ} \mathrm{C}$ for $10 \mathrm{~min}$, reverse transcription at $42^{\circ} \mathrm{C}$ for $45 \mathrm{~min}$, heat preservation at $72^{\circ} \mathrm{C}$ for $15 \mathrm{~min}$, followed by cooling on ice. Subsequently, the cDNA was used for qPCR using Taqman Universal Master mix II (Applied Biosystems; Thermo Fisher Scientific, Inc.) following the manufacturer's instructions. The qPCR thermocycling conditions were: $94^{\circ} \mathrm{C}$ for $90 \mathrm{sec}$ for an initial denaturation, 30 denaturation cycles at $95^{\circ} \mathrm{C}$ for $10 \mathrm{sec}$, followed by annealing and elongation at $60^{\circ} \mathrm{C}$ for $45 \mathrm{sec}$; and final extension at $72^{\circ} \mathrm{C}$ for $5 \mathrm{~min}$. For measuring the expression of PTEN, the first strand of cDNA was obtained by SuperScript III Platinum SYBR-Green One-Step RT-qPCR kit (Invitrogen; Thermo Fisher Scientific, Inc.) in a $15-\mathrm{min}$ incubation at $50^{\circ} \mathrm{C}$. qPCR was performed FastStart Universal SYBR-Green Master (Invitrogen; Thermo Fisher Scientific, Inc.). qPCR was performed on an Applied Biosystems (ABI PRISM) 7500 Fast Real-Time PCR system (Applied Biosystems; Thermo Fisher Scientific, Inc.). The qPCR conditions were: Pre-denaturation at $95^{\circ} \mathrm{C}$ for $3 \mathrm{~min}$ and 40 cycles of denaturation at $94^{\circ} \mathrm{C}$ for $30 \mathrm{sec}$ and annealing at $60^{\circ} \mathrm{C}$ for $45 \mathrm{sec}$. The primer sequences for RT-qPCR were as follows: miR-21 forward, 5'-GGGGTAGCTTATCAG ACTGATG-3' and reverse, 5'-TGTCGTGGAGCGGCAA TTG-3'; PTEN forward, 5'-GCAATATGTTCATAACGATGG CTGTGG-3' and reverse, 5'-GAACTGGCAGGTAGAAGG CAACTC-3'; $\beta$-actin forward, 5'-AGGGAAATCGTGCGT GAC-3' and reverse, 5'-CGCTCATTGCCGATAGTG-3'; and U6 forward, 5'-TGCGGGTGCTCGCTTCGGCAGC-3' and reverse, 5'-CCAGTGCAGGGTCCGAGGTA-3'. All primers were obtained from Sangon Biotech Co., Ltd. U6 was used for normalizing the level of miR-21 and $\beta$-actin was used to normalize the levels of PTEN. The experiment was performed in triplicate. The relative expression was quantified using the $2^{-\Delta \Delta \mathrm{Cq}}$ method (28).

Western blotting. Whole cell extracts from HUVECs treated with geniposide $(40 \mu \mathrm{M})$ for $1 \mathrm{~h}$ followed by treatment with ox-LDL $(50 \mu \mathrm{g} / \mathrm{ml})$ for $24 \mathrm{~h}$ were extracted using RIPA lysis buffer (Beyotime Institute of Biotechnology) supplemented with phenylmethanesul-fonyl (PMSF; Beyotime Institute of Biotechnology), and the protein concentration was quantified using a bicinchoninic acid kit (Beyotime Institute of Biotechnology). Proteins (30 $\mu \mathrm{g} /$ lane) were separated by SDS-PAGE on a $12 \%$ gel and transferred to polyvinylidene fluoride membranes (EMD Millipore). Following blocking with $5 \%$ skimmed milk for $2 \mathrm{~h}$ at room temperature, membranes were incubated with primary antibodies against PTEN (cat. no. 9188), Bax (cat. no. 5023), Bcl-2 (cat. no. 15071), Nox2 (cat. no. 4312) and GAPDH (cat. no. 5174) (all 1:2,000; all purchased from Cell Signaling Technology, Inc.) at $4^{\circ} \mathrm{C}$ overnight. Following three 10-min PBS washes, membranes were incubated with horseradish peroxidase-conjugated secondary antibody (1:5,000; Santa Cruz Biotechnology, Santa Cruz, Inc; cat. no. sc-2357) at room temperature for $90 \mathrm{~min}$, and the bands were visualized with an enhanced chemiluminescence reagent (GE Healthcare). GAPDH served as the internal control for total protein. The relative expression of each protein was normalized to endogenous control GAPDH using the Image Lab $^{\text {TM }} 4.4$ software (Bio-Rad Laboratories, Inc.).

Quantitative detection of $I L-1 \beta, I L-6, T N F-\alpha$ and IL-10 levels by enzyme-linked immunosorbent assay (ELISA). HUVECs 
were seeded onto 6 -well plates with $1 \times 10^{6}$ cells/well and treated as aforementioned. The levels of inflammation-associated cytokines in the supernatant were measured using ELISA kits (PeproTech, Inc.), including kits for IL-1 $\beta$ (cat. no. 900-M91), IL-6 (cat. no. 900-K50), TNF- $\alpha$ (cat. no. 900-K73) and IL-10 (cat. no. 900-M53). Briefly, culture medium was collected and centrifuged at $300 \mathrm{x} \mathrm{g}$ for $10 \mathrm{~min}$ at $4^{\circ} \mathrm{C}$ to obtain the supernatants for the measurement of IL- $1 \beta$, IL- 6 , TNF- $\alpha$ and IL-10 levels in accordance with the manufacturer's instructions. The supernatants of different concentrations standards (100 $\mu \mathrm{l})$ were added to pre-coated enzyme plates separately. Then, detection antibody as part of the aforementioned kits (50 $\mu \mathrm{l} ; 1: 100)$ was added to each well and incubated at room temperature for $90 \mathrm{~min}$. After washing six times, streptavidin labeled with horseradish peroxidase (1:100) was added to each pore and incubated at room temperature for $30 \mathrm{~min}$. Following incubation with chromogenic substrate (TMB; $100 \mu \mathrm{l}$; included in the kits) at room temperature for 5-30 min in dark, termination solution $(100 \mu \mathrm{l})$ was added to each well. The absorbance at $450 \mathrm{~nm}$ was read with a microplate reader.

Statistical analysis. The data were analyzed by GraphPad Prism 6 software (GraphPad Software, Inc.). All quantitative data were performed in triplicate and expressed as the mean \pm standard deviation. Statistical comparisons between various groups were performed with one-way analysis of variance analysis followed by a Tukey's post-hoc test. $\mathrm{P}<0.05$ was considered to indicate a statistically significant difference.

\section{Results}

Geniposide attenuates HUVECs injury and promotes the miR-21/PTEN pathway in HUVECs exposed to ox-LDL. Firstly, the damage of ox-LDL to HUVECs was investigated. The MTT assay results demonstrated that ox-LDL significantly decreased the viability of HUVECs in a concentration-dependent manner (Fig. 1A). Since $50 \mu \mathrm{g} / \mathrm{ml}$ ox-LDL was the lowest concentration to reduce cell viability to $\sim 60 \%$ compared with the control group, this concentration was selected for subsequent study. To illustrate the physiological effect of geniposide on injury induced by ox-LDL in HUVECs, HUVECs were pretreated with different concentrations of geniposide $(5,10$, 20, 40 and $80 \mu \mathrm{M}$ ) for $30 \mathrm{~min}$ and then treated with ox-LDL $(50 \mu \mathrm{g} / \mathrm{ml})$ for $24 \mathrm{~h}$. The MTT assay results demonstrated that pretreatment with geniposide (10,20,40 and $80 \mu \mathrm{M}$ for $30 \mathrm{~min})$ led to a significant suppression of ox-LDL-induced decrease in cell viability (Fig. 1B), while $5 \mu \mathrm{M}$ geniposide had no effect on the ox-LDL-induced downregulation of cell viability. Additionally, the LDH release analysis results (Fig. 1C) indicated that ox-LDL $(50 \mu \mathrm{g} / \mathrm{ml})$ significantly increased LDH activity compared with the control, whereas these effects were significantly reversed by geniposide $(5,10,20,40$ and $80 \mu \mathrm{M})$. Notably, MTT and LDH release analysis results revealed that $40 \mu \mathrm{M}$ geniposide markedly attenuated ox-LDL injury in HUVECs, which was considered as an appropriate concentration for subsequent studies. Furthermore, the effects of geniposide on the miR-21/PTEN pathway in ox-LDL-treated HUVECs were investigated. As presented in Fig. 1, ox-LDL (50 $\mu \mathrm{g} / \mathrm{ml})$ significantly decreased miR-21 level (Fig. 1D) and increased PTEN expression (Fig. 1E and F) compared with the control group, whereas these effects were reversed by geniposide $(40 \mu \mathrm{M})$. Geniposide treatment alone had no effects on miR-21 and PTEN. These results suggest that the miR-21/PTEN pathway may contribute to the cardioprotection of geniposide against ox-LDL-induced injury in HUVECs.

Geniposide inhibits apoptosis induced by ox-LDL in HUVECs. The impacts of geniposide on apoptosis were subsequently investigated. As presented in Fig. 2, Annexin V-FITC/PI staining results showed that geniposide pretreatment significantly reversed the ox-LDL-induced upregulation of the apoptotic rate (Fig. 2A and B). Bax and Bcl-2, members of the Bcl-2 protein family, are involved in mitochondria-mediated apoptosis (29). Western blotting confirmed that ox-LDL-induced a significant increase in Bax (a pro-apoptotic protein) expression and a significant decrease in Bcl-2 (an anti-apoptotic protein) expression, whereas these effects were both significantly reversed by geniposide (Fig. 2C). Caspase-3 is an effector enzyme involved in cell apoptosis (30). The results further demonstrated that the ox-LDL-induced upregulation of caspase-3 activity was also significantly attenuated by geniposide (Fig. 2D). In addition, ox-LDL resulted in a reduced MMP, which was also significantly reversed by geniposide (Fig. 2E). Geniposide alone had no effects on apoptosis in HUVECs. Overall, these results suggested that geniposide attenuated ox-LDL-induced apoptosis in HUVECs.

miR-21/PTEN pathway mediates the protection of geniposide against ox-LDL-induced injury in HUVECs. To further confirm the role of the miR-21/PTEN pathway in the beneficial action of geniposide, HUVECs were transfected with miR-21 mimic or inhibitor, in order to overexpress or knockdown miR-21 expression. RT-qPCR results revealed that the miR-21 mimic-transfected cells demonstrated significantly increased miR-21 level, whereas the miR-21 inhibitor significantly decreased miR-21 level in HUVECs compared with the miR-NC transfection group (Fig. 3A). Studies have revealed that PTEN is the negatively regulated target of miR-21 $(31,32)$. Western blot analysis revealed that the miR-21 mimic led to a significant downregulation of PTEN expression, whereas the miR-21 inhibitor led to a significant upregulation of PTEN expression (Fig. 3B and C), indicating enhancement of the miR-21/PTEN pathway induced by miR-21 mimic and inhibition of the miR-21/PTEN pathway induced by miR-21 inhibitor. In addition, miR-21 mimic further aggravated geniposide-induced increase in cell viability (Fig. 3D) and the decrease in LDH activity (Fig. 3E), whereas the miR-21 inhibitor had the opposite effects. The geniposide-induced the decreases in caspase- 3 activity (Fig. 3F) and apoptosis rate (Fig. 3G and $\mathrm{H}$ ) were also exacerbated by miR-21 mimic and blocked by miR-21 inhibitor, compared with miR-NC transfection group. Furthermore, the geniposide-induced downregulation of Bax expression and upregulation of Bcl-2 expression (Fig. 3I and K) were promoted by miR-21 mimic and reversed by miR-21 inhibitor under ox-LDL condition. Overall, these results indicated that the miR-21/PTEN pathway mediated the protection of geniposide against ox-LDL-induced injury in HUVECs.

miR-21/PTEN pathway contributes to the inhibition of geniposide on ox-LDL-induced oxidative stress in HUVECs. 

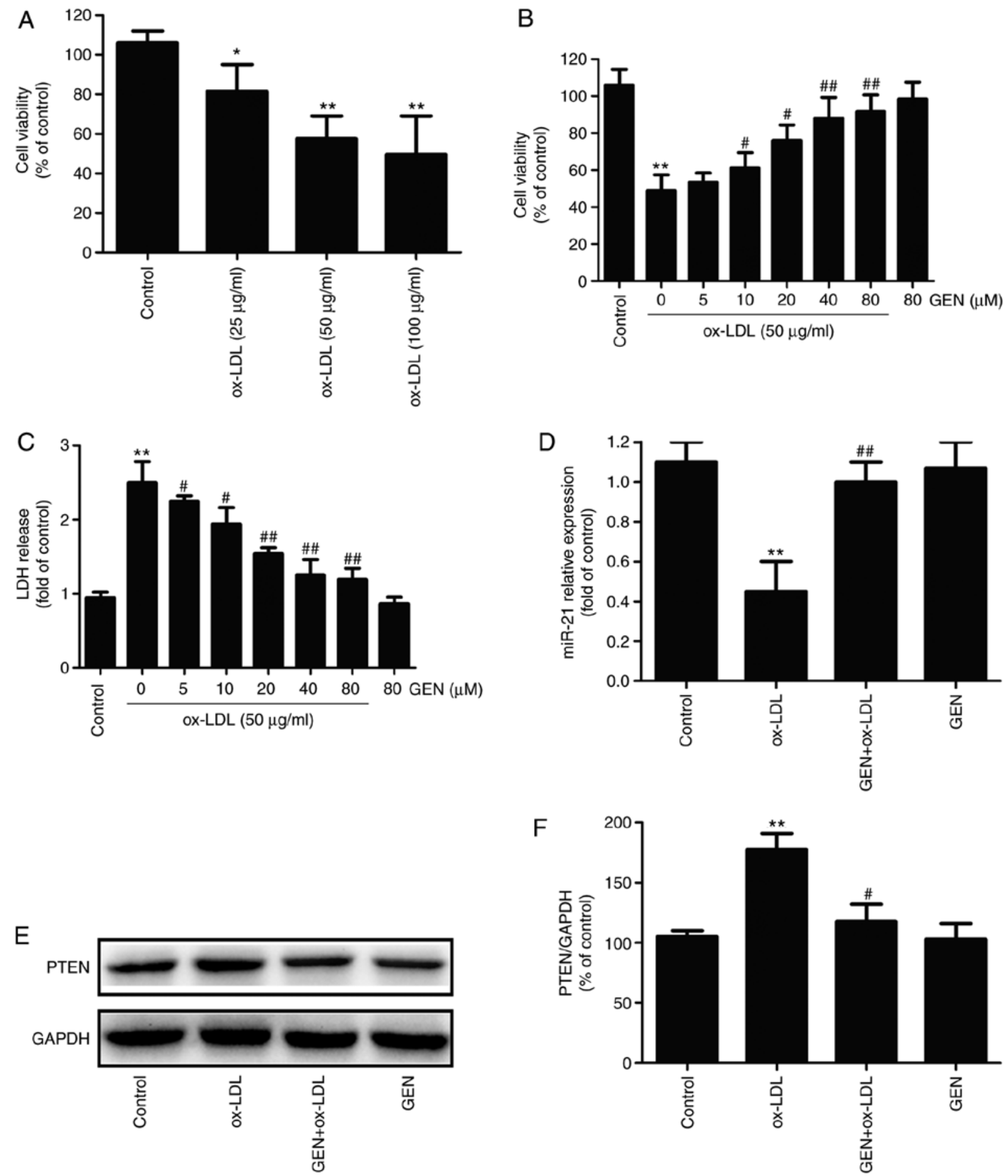

Figure 1. Effect of geniposide and ox-LDL on cell viability, LDH activity and miR-21/PTEN pathway in HUVECs. (A) HUVECs were treated with ox-LDL $(25,50$ and $100 \mu \mathrm{g} / \mathrm{ml})$ for $24 \mathrm{~h}$, and the cell viability was detected by MTT assay. (B) HUVECs were pretreated with geniposide $(5,10,20,40$ and $80 \mu \mathrm{M})$ for $30 \mathrm{~min}$ followed by treatment with ox-LDL $(50 \mu \mathrm{g} / \mathrm{ml})$ for $24 \mathrm{~h}$, and the cell viability was detected by MTT assay. (C) The LDH activity was determined by a commercially available Cytotoxicity LDH assay kit. HUVECs were pretreated with geniposide $(40 \mu \mathrm{M})$ for $1 \mathrm{~h}$ followed by treatment with ox-LDL $(50 \mu \mathrm{g} / \mathrm{ml})$ for $24 \mathrm{~h}$. (D) The level of miR-21 was detected by reverse transcription-quantitative PCR. (E) The expression of PTEN was measured by western blot analysis. (F) Quantitative densitometric analysis of PTEN expression. Data are shown as mean \pm standard deviation, $\mathrm{n}=3$. ${ }^{*} \mathrm{P}<0.05$, ${ }^{* *} \mathrm{P}<0.01$ vs. control group; ${ }^{\#} \mathrm{P}<0.05$, ${ }^{\# \#} \mathrm{P}<0.01$ vs. ox-LDL alone group. GEN, geniposide; ox-LDL, oxidized low-density lipoprotein; PTEN, phosphate and tension homolog; miR, microRNA; LDH, lactate dehydrogenase; HUVECs, human umbilical vein endothelial cells.

To further investigate the role of the miR-21/PTEN pathway on the impact of geniposide on oxidative stress under ox-LDL condition, oxidative stress markers including ROS generation, MDA content and Nox2 expression were detected. As shown in Fig. 4, DCFH-DA staining results (Fig. 4A) showed that geniposide pretreatment obviously attenuated ox-LDL-induced increase in ROS generation (Fig. 4B), MDA content (Fig. 4C) and Nox 2 expression (Fig. 4D and E) in HUVECs compared with the ox-LDL group. However, these effects were exacerbated by miR-21 mimic and reversed by miR-21 inhibitor. Additionally, geniposide eliminated ox-LDL-induced decreases in antioxidant enzyme activities, including SOD 
A Control

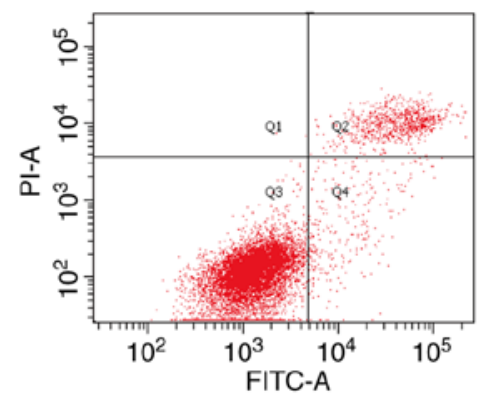

GEN+ox-LDL

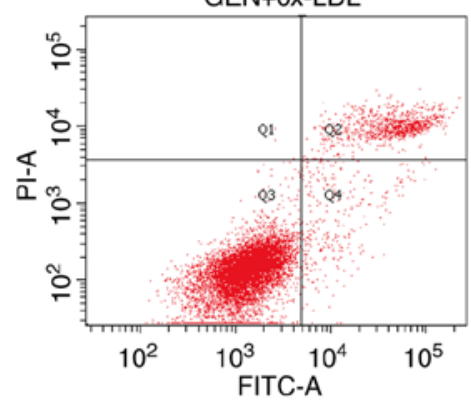

B

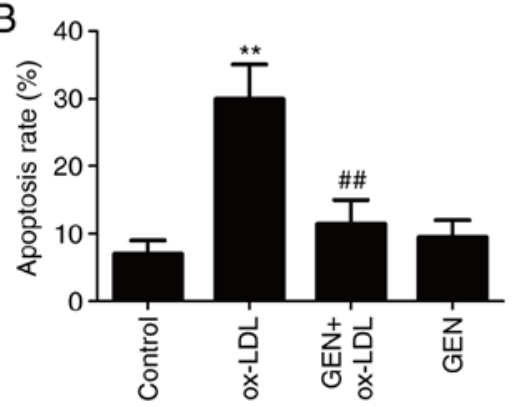

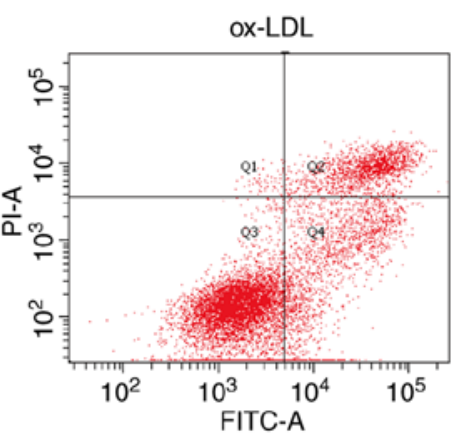
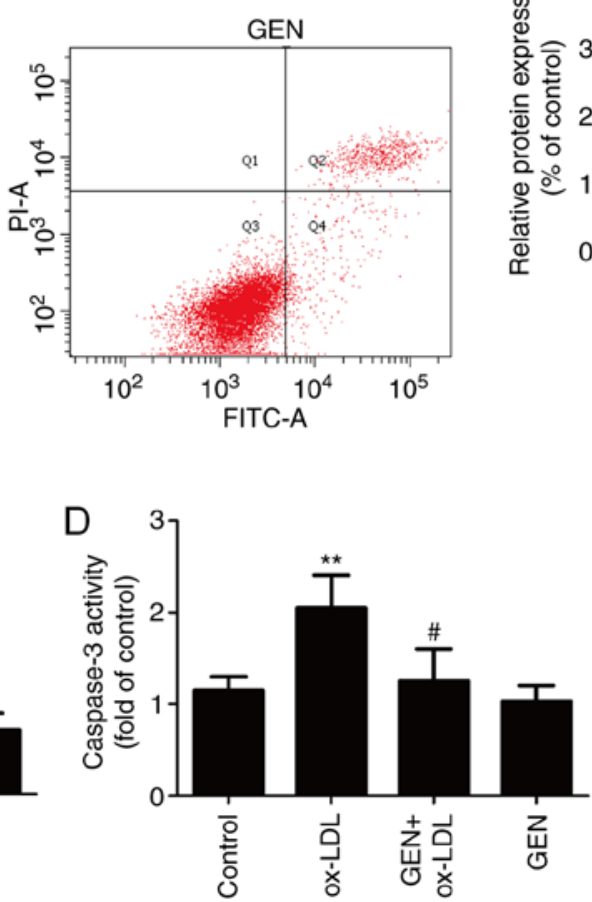
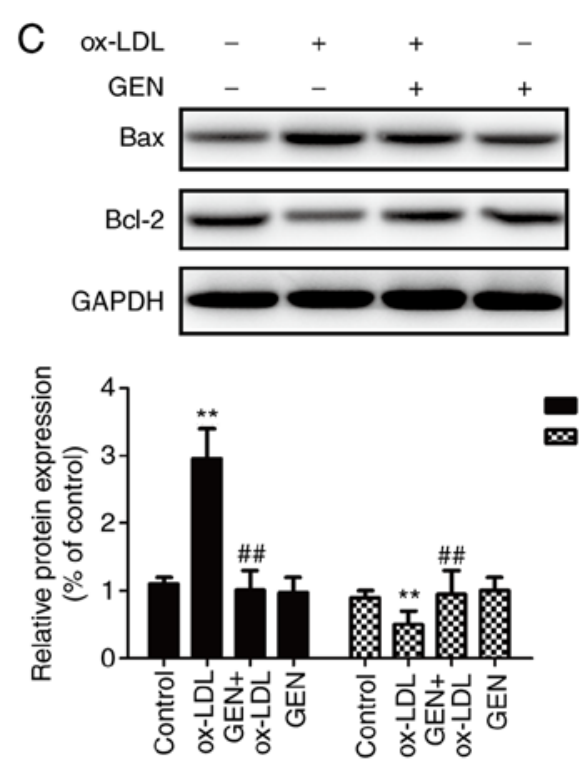

Figure 2. Effect of geniposide on apoptosis in HUVECs subjected to ox-LDL. HUVECs were pretreated with geniposide (40 $\mu \mathrm{M}$ ) for $1 \mathrm{~h}$ and treated with ox-LDL $(50 \mu \mathrm{g} / \mathrm{ml})$ for $24 \mathrm{~h}$. (A) The apoptosis rate was assayed by Annexin V-FITC/PI Apoptosis Detection kit. (B) Analysis of the flow cytometry data. (C) The expression of Bax and Bcl-2 were determined by western blot analysis. (D) The caspase-3 activity was evaluated by a caspase-3 assay kit. (E) The MMP was determined by JC-1 staining kit. Data are shown as mean \pm standard deviation, $\mathrm{n}=3 .{ }^{*} \mathrm{P}<0.05,{ }^{* *} \mathrm{P}<0.01$ vs. control group. ${ }^{\#} \mathrm{P}<0.05,{ }^{\# \#} \mathrm{P}<0.01$ vs. ox-LDL treatment group. GEN, geniposide; ox-LDL, oxidized low-density lipoprotein; FITC, fluorescein isothiocyanate; PI, propidium iodide; MMP, mitochondrial membrane potential; HUVECs, human umbilical vein endothelial cells.

(Fig. 4F), GSH-PX (Fig. 4G) and CAT (Fig. 4H), which were strengthened by miR-21 mimic and reversed by miR-21 inhibitor. Overall, these results demonstrated that miR-21 is involved in the anti-oxidative stress of geniposide in ox-LDL injury.

miR-21/PTEN contributes to geniposide-induced anti-inflammatory action in ox-LDL-treated HUVECs. Finally, the effects of geniposide on ox-LDL-induced inflammatory response in HUVECs were further explored. As shown in Fig. 5, the ELISA results revealed that geniposide significantly reversed the ox-LDL-induced upregulation of pro-inflammatory cytokines, such as IL-1 $\beta$ (Fig. 5A), IL-6 (Fig. 5B) and TNF- $\alpha$ (Fig. 5C), compared with the ox-LDL alone group. However, these actions of geniposide were aggravated by miR-21 mimic and suppressed by miR-21 inhibitor. In addition, the geniposide-induced increase in the anti-inflammatory cytokine IL-10 level was also further significantly promoted by miR-21 mimic and mitigated by miR-21 inhibitor (Fig. 5D). Overall, these results demonstrated that geniposide inhibited the inflammatory response induced by ox-LDL via the upregulation of miR-21/PTEN.

\section{Discussion}

The present study first demonstrated that geniposide protects against atherosclerotic damage by inhibiting oxidative stress and inflammation, via enhancing the miR-21/PTEN pathway in in vitro experiments.

The pathogenesis of atherosclerosis has been extensively studied, such as endothelial cell damage, apoptosis, inflammatory response, oxidative stress and calcium overload $(33,34)$. Geniposide, an iridoid glucoside, is involved in maintaining multiple beneficial actions depending on its anti-inflammatory and anti-oxidative activities $(17,35,36)$. Emerging evidence has revealed the protective effects of geniposide on the development of atherosclerosis $(17,37,38)$. Consistent with these previous studies, the present study also found that geniposide pretreatment attenuated ox-LDL-induced HUVECs injury and apoptosis. It is understood that excessive apoptosis contributes 

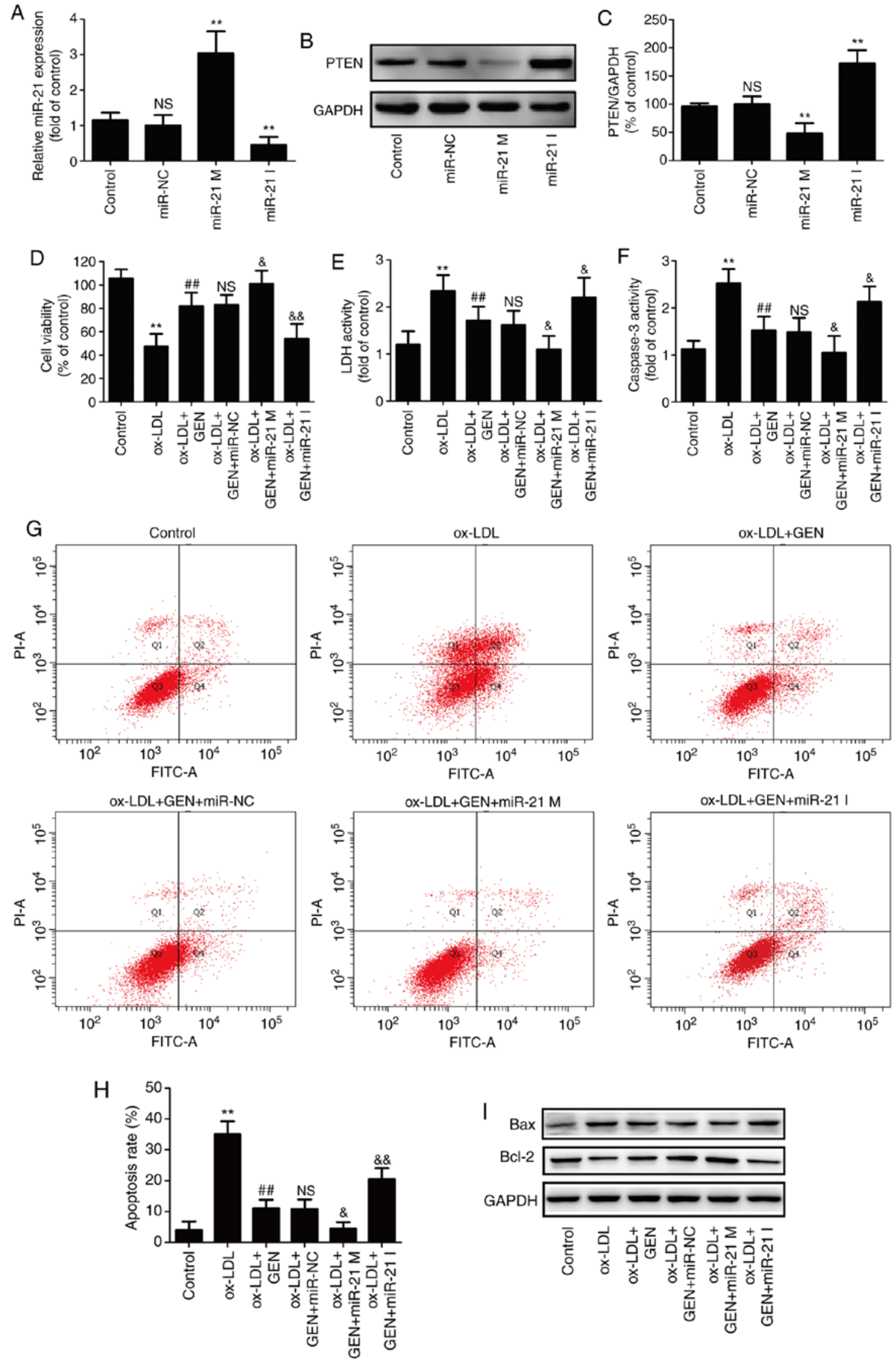

Figure 3. Effects of miR-21 upregulation or downregulation on the miR-21/PTEN pathway and the protection of geniposide against ox-LDL injury in HUVECs. HUVECs were transfected with miR-21 mimic, miR-21 inhibitor or miR-NC and then treated with geniposide ( $40 \mu \mathrm{M})$ for $1 \mathrm{~h}$ followed by ox-LDL $(50 \mu \mathrm{g} / \mathrm{ml})$ treatment for $24 \mathrm{~h}$. (A) miR-21 level was quantified by reverse transcription-quantitative PCR assay. (B) PTEN expression was measured by western blot analysis. (C) Quantitative analysis of PTEN expression. ${ }^{* *} \mathrm{P}<0.01$ vs. miR-NC transfection group. (D) The viability of HUVECs was detected by MTT assay. (E) The activity of LDH activity was evaluated by a LDH commercially available Cytotoxicity LDH Assay kit. (F) The activity of caspase-3 was assayed by a caspase-3 assay kit. (G) The apoptosis rate was analyzed by Annexin V-FITC/PI Apoptosis Detection kit. (H) Quantitative densitometric analysis of apoptosis rate was determined by flow cytometry. (I) The expressions of Bax and $\mathrm{Bcl}-2$ were determined by western blot analysis. 

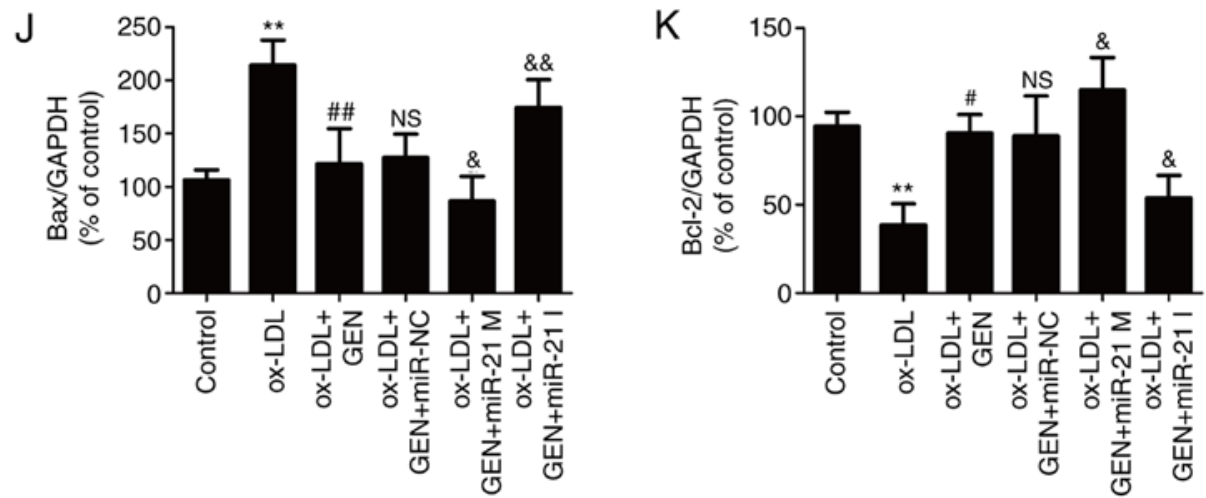

Figure 3. Continued. Quantitative analysis of $(\mathrm{J})$ Bax and $(\mathrm{K}) \mathrm{Bcl}-2$ expression. Data are shown as mean \pm standard deviation, $\mathrm{n}=3$. ${ }^{* *} \mathrm{P}<0.01 \mathrm{vs}$. control group; ${ }^{\#} \mathrm{P}<0.05,{ }^{\# \prime} \mathrm{P}<0.01$ vs. ox-LDL treatment group; ${ }^{\mathrm{P}} \mathrm{P}<0.05$, \& ${ }^{\&} \mathrm{P}<0.01$ vs. ox-LDL + miR-21 co-treatment group. GEN, geniposide; ox-LDL, oxidized low-density lipoprotein; miR-21 M, miR-21 mimic; miR-21 I, miR-21 inhibitor; miR-NC, miRNA negative control; NS, no significance; LDH, lactate dehydrogenase; HUVECs, human umbilical vein endothelial cells; FITC, fluorescein isothiocyanate; PI, propidium iodide.

A

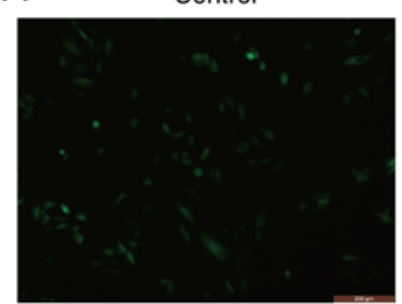

ox-LDL+GEN+miR-NC

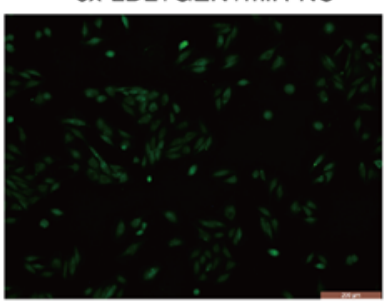

B

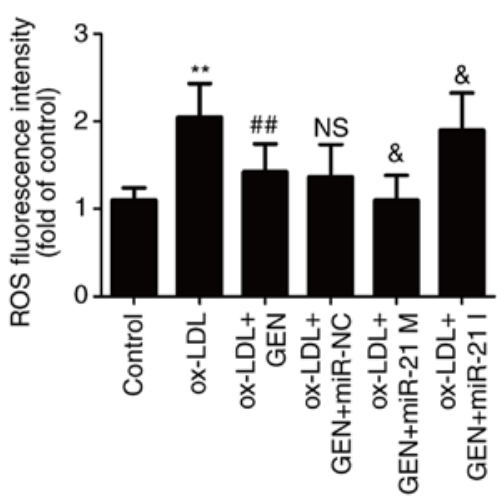

ox-LDL

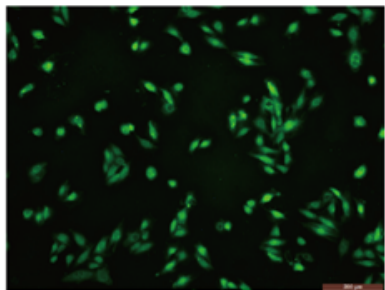

ox-LDL+GEN+miR-21 M

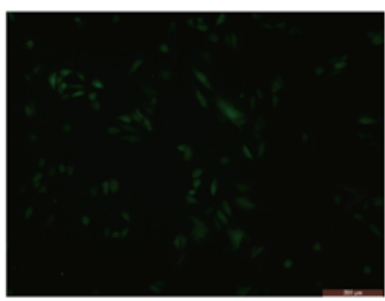

C

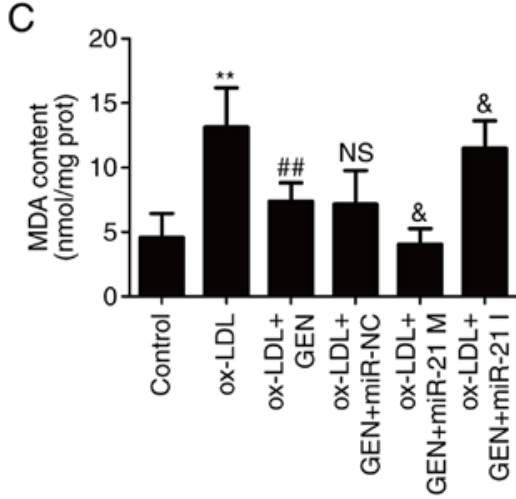

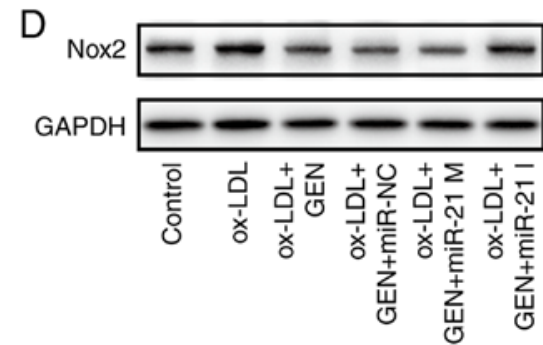

Figure 4. Effects of geniposide oxidative stress in the presence or absence of miR-21 mimic or inhibitor in ox-LDL-treated HUVECs. HUVECs were transfected with miR-21 mimic or miR-21 inhibitor or miR-NC and then treated with geniposide $(40 \mu \mathrm{M})$ for $1 \mathrm{~h}$ prior to ox-LDL (50 $\mu \mathrm{g} / \mathrm{ml})$ treatment for $24 \mathrm{~h}$. (A) The ROS production was analyzed by DCFH-DA staining. Magnification, x200. (B) Quantitative densitometric analysis of ROS level was determined. (C) The MDA content was measured by a commercial kit. (D) Nox2 expression was measured by western blot analysis. 
E

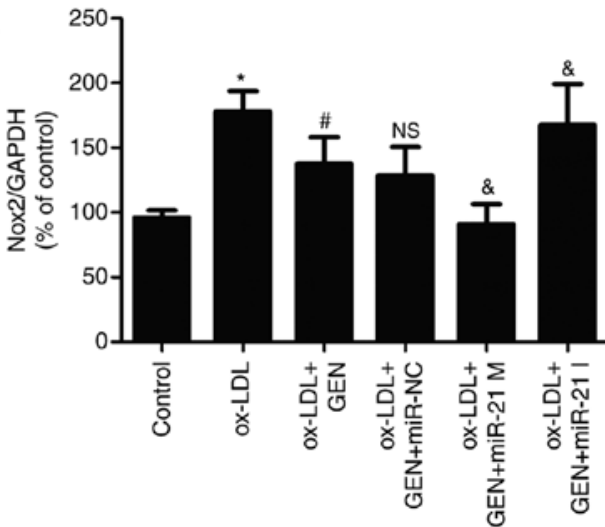

G

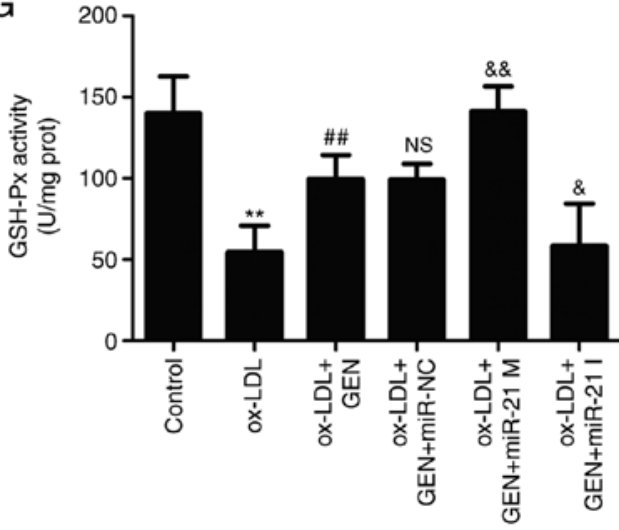

$\mathrm{F}$

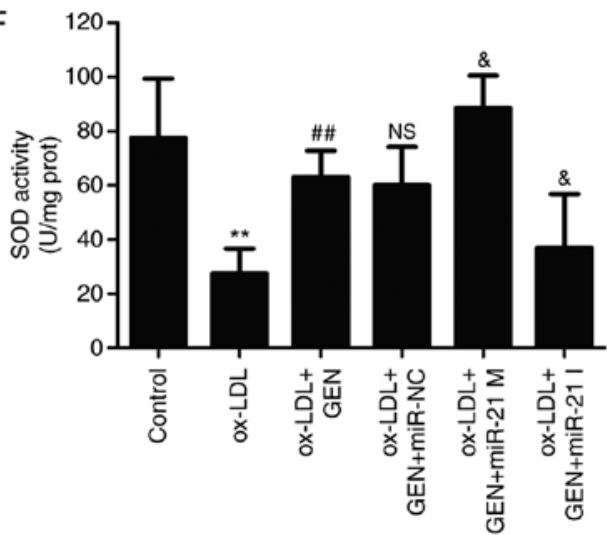

$\mathrm{H}$

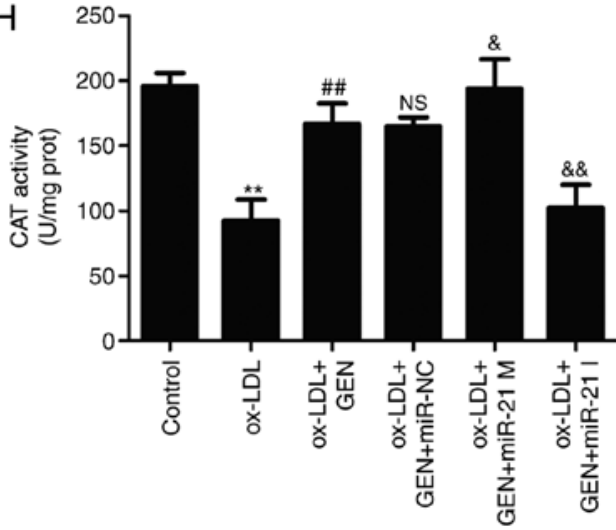

Figure 4. Continued. (E) Quantitative densitometric analysis of Nox2 expression. (F) SOD, (H) GSH-Px and (G) CAT activities were determined by commercial kits. Data are shown as mean \pm standard deviation, $\mathrm{n}=3 .{ }^{*} \mathrm{P}<0.05,{ }^{* *} \mathrm{P}<0.01$ vs. control group. ${ }^{\#} \mathrm{P}<0.05,{ }^{\# \#} \mathrm{P}<0.01$ vs. ox-LDL treatment group. ${ }^{\star} \mathrm{P}<0.05$, \&\&P<0.01 vs. ox-LDL + GEN + miR-NC co-treatment group. GEN, geniposide; ox-LDL, oxidized low-density lipoprotein; miR-21 M, miR-21 mimic; miR-21 I, miR-21 inhibitor; miR-NC, miRNA negative control; NS, no significance; ROS, reactive oxygen species; MDA, malondialdehyde; Nox2, NADPH oxidase 2; SOD, peroxide dismutase; GSH-PX, glutathione peroxidase; CAT, catalase; HUVECs, human umbilical vein endothelial cells.

to cell death invariably following atherosclerosis (39). These results indicated that geniposide protects HUVECs against ox-LDL injury via inhibiting apoptosis.

miR-21, a highly expressed miRNA in the heart, has a crucial function of modulating normal biological processes of the myocardial tissue (40). Accumulating evidence also suggests that the miR-21/PTEN pathway exhibits critical actions on cell survival and death in the cardiovascular system $(24,41,42)$. As previously reported, miR-21 expression is decreased, whereas PTEN is upregulated following high glucose (HG) treatment in endothelial cells, implying that miR-21/PTEN could be an effective therapeutic target for the treatment of $\mathrm{HG}$-induced vascular injury (42). Another study revealed that the decrease in miR-21 level is accompanied by the increase of nitrogen dioxide PTEN expression under hypoxia/reperfusion condition in cardiomyocytes, and miR-21/PTEN pathway activation counteracted the anti-apoptotic effect of trimetazidine, an anti-ischemic and antioxidant agent, on hypoxia/reperfusion injury (25). However, to the best of our knowledge, the association between geniposide and miR-21/PTEN has not yet been reported. The present study found that ox-LDL treatment significantly resulted in inhibition of the miR-21/PTEN pathway, which is consistent with previous studies $(24,43)$. Notably, these effects were reversed by geniposide pretreatment, indicating geniposide induced the activation of the miR-21/PTEN pathway under ox-LDL condition. Additionally, miR-21 mimic transfection further promoted geniposide-induced protection against ox-LDL injury, while miR-21 inhibitor transfection remarkably attenuated geniposide-induced protection against ox-LDL injury. Overall, these results suggested that the miR-21/PTEN pathway mediated geniposide-induced cardioprotection against ox-LDL injury. In addition, studies have demonstrated the roles of the miR-21/PTEN pathway in tumor growth, migration and invasion $(44,45)$. Combined with previous studies regarding the protection of geniposide against tumor $(15,46)$, miR-21/PTEN pathway may contribute to the antitumor effect of geniposide.

Excess ROS generation-induced oxidative stress has emerged as a critical, final universal mechanism in atherosclerosis (47). An imbalance in the oxidant (non-enzymatic and enzymatic, MPO and NADH oxidase)/anti-oxidant mechanisms (GSH, Vitamins, Gpx, Prdx, SOD and PON) induces excess ROS production, leading to a state of atherogenic plaque formation (48). Geniposide exerts beneficial activities in human diseases by inhibiting oxidative stress injury (49-51). Geniposide decreases intracellular ROS accumulation and enhances the antioxidant enzymatic SOD and CAT activities in $\mathrm{H}_{2} \mathrm{O}_{2}$-treated melanocytes (49). Geniposide also enhances mitochondrial function via attenuating oxidative stress and MDA, and enhancing the antioxidant defense system, resulting in the inhibition of cardiomyocyte apoptosis and protection against hypoxia/reoxygenation injury (14). However, the 
A
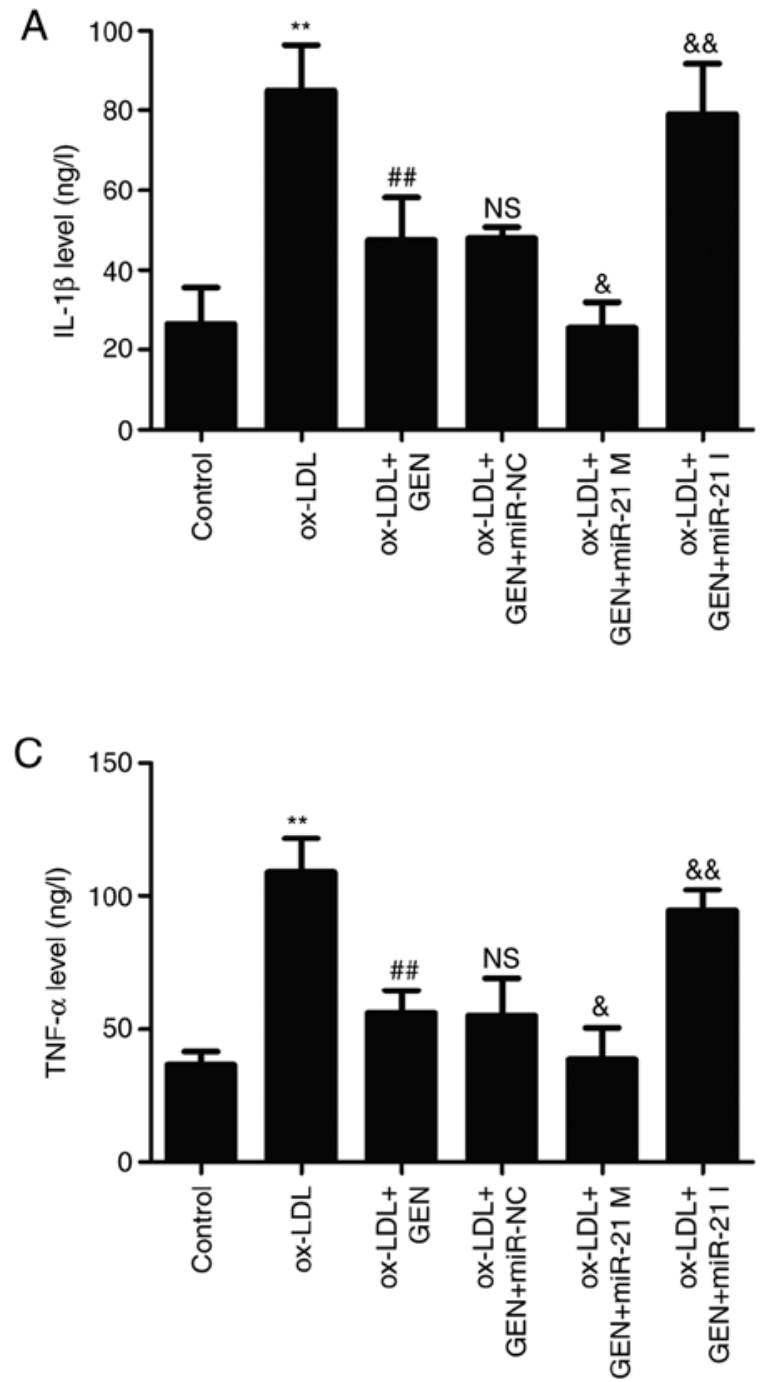

B
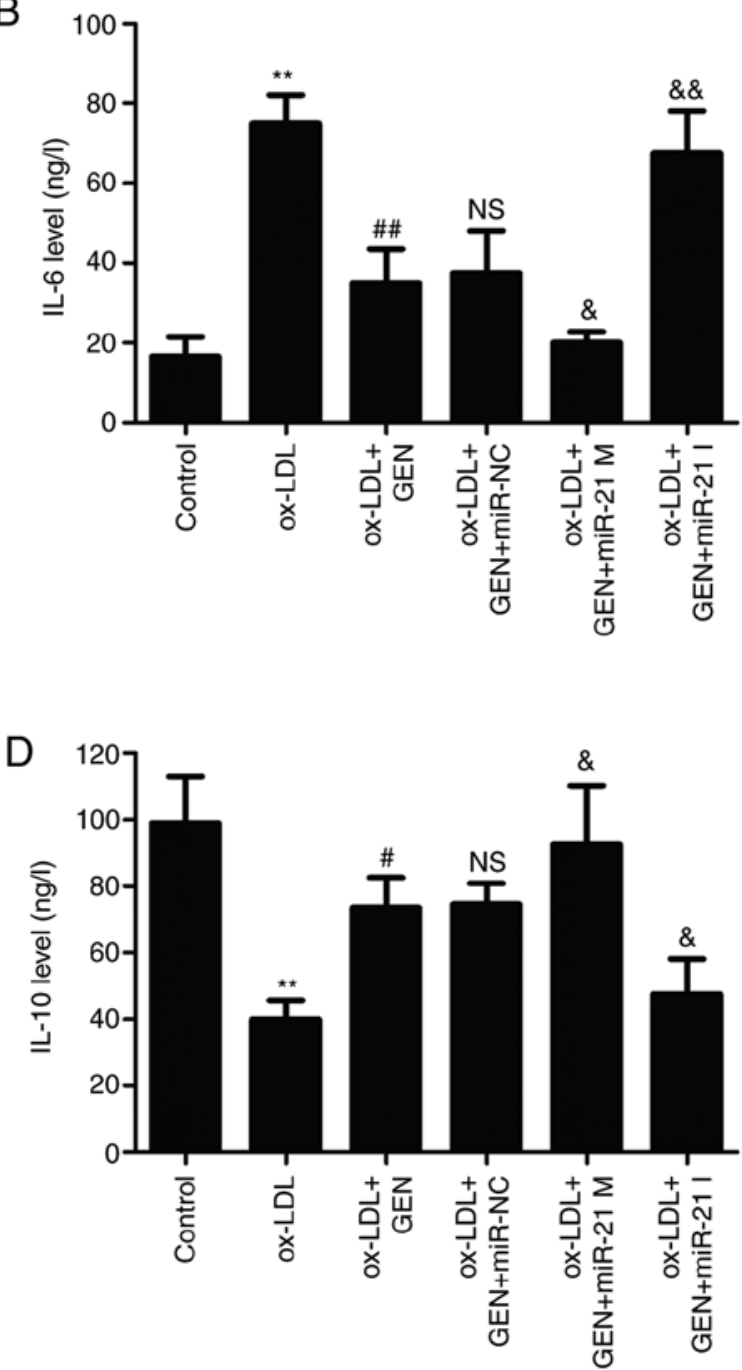

Figure 5. Effects of geniposide inflammatory cytokine levels in the presence or absence of miR-21 M or miR-21 I in ox-LDL-treated HUVECs. HUVECs were transfected with miR-21 mimic M, miR-21 I or miR-NC and then treated with geniposide ( $40 \mu \mathrm{M})$ for $1 \mathrm{~h}$ prior to ox-LDL $(50 \mu \mathrm{g} / \mathrm{ml})$ treatment for $24 \mathrm{~h}$. The levels of (A) IL-1 $\beta$, (B) IL-6, (C) TNF- $\alpha$ and (D) IL-10 in the culture supernatant were detected by enzyme-linked immunosorbent assay kits. Data are shown as means \pm standard deviation, $n=3 .{ }^{* *} \mathrm{P}<0.01$ vs. control group. ${ }^{\#} \mathrm{P}<0.05,{ }^{\# / t} \mathrm{P}<0.01$ vs. ox-LDL treatment group; ${ }^{\&} \mathrm{P}<0.05$, \&\& $\mathrm{P}<0.01$ vs. ox-LDL + GEN + miR-NC co-treatment group. GEN, geniposide; ox-LDL, oxidized low-density lipoprotein; miR-21 M, miR-21 mimic; miR-21 I, miR-21 inhibitor; miR-NC, miRNA negative control; NS, no significance.

antioxidant characteristic of geniposide in atherosclerosis has not been demonstrated. The present study found that geniposide mitigated the ox-LDL-induced upregulation of ROS generation and MDA content, and the downregulation of SOD, GSH-Px and CAT activities, inhibiting oxidative stress and promoting antioxidant defense system. Notably, the present study further found that miR-21 mimic exacerbated the inhibition of geniposide on oxidative stress, whereas miR-21 inhibitor blocked the inhibition of geniposide in ox-LDL-treated HUVECs, which was consistent with previous studies associated with the anti-oxidative activity of miR-21 $(52,53)$. These results indicated that miR-21/PTEN contributed to anti-oxidative stress effects of geniposide in atherosclerosis.

Inflammation plays an important role during every phase of atherosclerosis development, and an increasing body of evidence suggests that inflammation resolution may become a potential approach in treatment of atherosclerosis $(54,55)$. A recent study reported that geniposide inhibits arterial plaque formation and eliminates the inflammatory response in $\mathrm{ApoE}^{-/-}$mice via regulating the miR-101/MKP-1/p38 pathway (17). Likewise, the present study revealed that geniposide pretreatment decreased pro-inflammatory cytokine (IL-1 $\beta$, IL-6 and TNF- $\alpha$ ) levels and increased the anti-inflammatory cytokine (IL-10) level in ox-LDL-treated HUVECs. miR-21 has been demonstrated to play an important role in the induction and resolution of inflammatory responses (56). The elimination of PTEN induced by dysregulated miR-21 promotes inflammatory responses (57). The present study further found that miR-21 mimic strengthened the anti-inflammatory effect of geniposide under ox-LDL condition in HUVECs, whereas the miR-21 inhibitor abolished the anti-inflammatory effect of geniposide. Taken together, these results indicated that the miR-21/PTEN pathway is involved in the anti-inflammatory effect of geniposide in atherosclerosis.

The present study also has some limitations. Firstly, PTEN overexpression or knockdown should be considered to directly confirm the role of the miR-21/PTEN pathway in the anti-oxidant and anti-inflammatory effects of geniposide 
in atherosclerosis. Secondly, the present study was only an in vitro study, and the detailed underlying mechanism should be further demonstrated in animal models of atherosclerosis.

The present study provides evidence that geniposide protects against ox-LDL-induced endothelial injury, with suppressing oxidative stress and inflammatory response, which is associated with the enhancement of miR-21/PTEN pathways. These findings suggest that geniposide may exhibit clinical potential in the prevention of atherosclerosis, and these outcomes opened a new view of research regarding the role of the miR-21/PTEN pathway in the potential protective role of geniposide in a variety of diseases related to oxidative stress and inflammation.

\section{Acknowledgements}

Not applicable.

\section{Funding}

No funding was received.

\section{Availability of data and materials}

The datasets used and/or analyzed during the current study are available from the corresponding author on reasonable request.

\section{Authors' contributions}

SZ designed and performed the experiments, and wrote the manuscript. YS and $\mathrm{KZ}$ analyzed the data. YG, JC and LQ designed the experiments and analyzed the data. LH performed the experiments. All authors read and approved the final version of the manuscript.

\section{Ethics approval and consent to participate}

Not applicable.

\section{Patient consent for publication}

Not applicable.

\section{Competing interests}

The authors declare that they have no competing interests.

\section{References}

1. Fitridge $\mathrm{R}$ and Thompson $\mathrm{M}$ (eds): Mechanisms of Vascular Disease: A Reference Book for Vascular Specialists [Internet]. University of Adelaide Press, Adelaide, AU, 2011.

2. Benjamin EJ, Virani SS, Callaway CW, Chamberlain AM, Chang AR, Cheng S, Chiuve SE, Cushman M, Delling FN, Deo R, et al: Heart disease and stroke statistics-2018 update: A report from the American Heart Association. Circulation 137: e67-e492, 2018.

3. Libby P, Bornfeldt KE and Tall AR: Atherosclerosis: Successes, surprises, and future challenges. Circ Res 118: 531-534, 2016.

4. Lee DY and Chiu JJ: Atherosclerosis and flow: Roles of epigenetic modulation in vascular endothelium. J Biomed Sci 26: 56, 2019.
5. Gimbrone MA Jr and García-Cardeña G: Endothelial cell dysfunction and the pathobiology of atherosclerosis. Circ Res 118: 620-636, 2016.

6. Back M, Yurdagul A Jr, Tabas I, Oorni K and Kovanen PT: Inflammation and its resolution in atherosclerosis: Mediators and therapeutic opportunities. Nat Rev Cardiol 16: 389-406, 2019.

7. Yuan T, Yang T, Chen H, Fu D, Hu Y, Wang J, Yuan Q, Yu H, $\mathrm{Xu} \mathrm{W}$ and $\mathrm{Xie} X$ : New insights into oxidative stress and inflammation during diabetes mellitus-accelerated atherosclerosis. Redox Biol 20: 247-260, 2019.

8. Libby P, Buring JE, Badimon L, Hansson GK, Deanfield J, Bittencourt MS, Tokgözoğlu L and Lewis EF: Atherosclerosis. Nat Rev Dis Primers 5: 56, 2019.

9. Trpkovic A, Resanovic I, Stanimirovic J, Radak D, Mousa SA Cenic-Milosevic D, Jevremovic D and Isenovic ER: Oxidized low-density lipoprotein as a biomarker of cardiovascular diseases. Crit Rev Clin Lab Sci 52: 70-85, 2015.

10. Cao Y, Gong Y, Liu L, Zhou Y, Fang X, Zhang C, Li Y and Li J: The use of human umbilical vein endothelial cells (HUVECs) as an in vitro model to assess the toxicity of nanoparticles to endothelium: A review. J Appl Toxicol 37: 1359-1369, 2017.

11. Shangguan WJ, Zhang YH, Li ZC, Tang LM, Shao J and Li H: Naringin inhibits vascular endothelial cell apoptosis via endoplasmic reticulum stress and mitochondrialmediated pathways and promotes intraosseous angiogenesis in ovariectomized rats. Int J Mol Med 40: 1741-1749, 2017.

12. Cai L, Li CM, Tang WJ, Liu MM, Chen WN, Qiu YY and Li R. Therapeutic effect of penta-acetyl geniposide on adjuvant-induced arthritis in rats: Involvement of inducing synovial apoptosis and inhibiting NF- $\kappa B$ signal pathway. Inflammation 41: 2184-2195, 2018.

13. Pan T, Shi X, Chen H, Chen R, Wu D, Lin Z, Zhang J and Pan J: Correction to: Geniposide suppresses interleukin-1 $\beta$-induced inflammation and apoptosis in rat chondrocytes via the $\mathrm{PI} 3 \mathrm{~K} / \mathrm{Akt} / \mathrm{NF}-\kappa \mathrm{B}$ signaling pathway. Inflammation 42: 404-405, 2019.

14. Jiang YQ, Chang GL, Wang Y, Zhang DY, Cao L and Liu J: Geniposide prevents Hypoxia/Reoxygenation-Induced apoptosis in H9c2 Cells: Improvement of mitochondrial dysfunction and activation of GLP-1R and the PI3K/AKT signaling pathway. Cell Physiol Biochem 39: 407-421, 2016.

15. Habtemariam S and Lentini G: Plant-derived anticancer agents: Lessons from the pharmacology of geniposide and its aglycone, genipin. Biomedicines 6: pii: E39, 2018.

16. Koo HJ, Lee S, Shin KH, Kim BC, Lim CJ and Park EH: Geniposide, an anti-angiogenic compound from the fruits of Gardenia jasminoides. Planta Med 70: 467-469, 2004.

17. Cheng S, Zhou F, Xu Y, Liu X, Zhang Y, Gu M, Su Z, Zhao D, Zhang L and Jia Y: Geniposide regulates the miR-101/MKP-1/p38 pathway and alleviates atherosclerosis inflammatory injury in ApoE(-/-) mice. Immunobiology 224: 296-306, 2019.

18. Wang B, Liao PP, Liu LH, Fang X, Li W and Guan SM: Baicalin and geniposide inhibit the development of atherosclerosis by increasing Wnt1 and inhibiting dickkopf-related protein-1 expression. J Geriatr Cardiol 13: 846-854, 2016.

19. Bhaskaran M and Mohan M: MicroRNAs: History, biogenesis, and their evolving role in animal development and disease. Vet Pathol 51: 759-774, 2014.

20. Kumarswamy R, Volkmann I and Thum T: Regulation and function of miRNA-21 in health and disease. RNA Biol 8: 706-713, 2011.

21. Juźwik CA, S Drake S, Zhang Y, Paradis-Isler N, Sylvester A, Amar-Zifkin A, Douglas C, Morquette B, Moore CS and Fournier AE: microRNA dysregulation in neurodegenerative diseases: A systematic review. Prog Neurobiol 182: 101664, 2019.

22. Cheng Y and Zhang C: MicroRNA-21 in cardiovascular disease. J Cardiovasc Transl Res 3: 251-255, 2010.

23. Jazbutyte V and Thum T: MicroRNA-21: From cancer to cardiovascular disease. Curr Drug Targets 11: 926-935, 2010.

24. Li FP, Lin DQ and Gao LY: LncRNA TUG1 promotes proliferation of vascular smooth muscle cell and atherosclerosis through regulating miRNA-21/PTEN axis. Eur Rev Med Pharmacol Sci 22: 7439-7447, 2018

25. Yang Q, Yang K and Li AY: Trimetazidine protects against hypoxia-reperfusion-induced cardiomyocyte apoptosis by increasing microRNA-21 expression. Int J Clin Exp Pathol 8: 3735-3741, 2015.

26. Canfrán-Duque A, Rotllan N, Zhang X, Fernández-Fuertes M, Ramírez-Hidalgo C, Araldi E, Daimiel L, Busto R, FernándezHernando C and Suárez Y: Macrophage deficiency of miR-21 promotes apoptosis, plaque necrosis, and vascular inflammation during atherogenesis. EMBO Mol Med 9: 1244-1262, 2017. 
27. Chipont A, Esposito B, Challier I, Montabord M, Tedgui A, Mallat Z, Loyer X and Potteaux S: Microrna-21 deficiency alters the survival of ly-6clo monocytes in apoe $e^{-/-}$mice and reduces early-stage atherosclerosis-brief report. Arterioscler Thromb Vasc Biol 39: 170-177, 2019.

28. Livak KJ and SchmittgenTD: Analysis of relative gene expression data using real-time quantitative PCR and the 2 (-Delta Delta C(T)) method. Methods 25: 402-408, 2001.

29. Murphy KM, Ranganathan V, Farnsworth ML, Kavallaris M and Lock RB: Bcl-2 inhibits Bax translocation from cytosol to mitochondria during drug-induced apoptosis of human tumor cells. Cell Death Differ 7: 102-111, 2000.

30. Riedl SJ and Shi Y: Molecular mechanisms of caspase regulation during apoptosis. Nat Rev Mol Cell Biol 5: 897-907, 2004.

31. Guo X, Qiu W, Liu Q, Qian M, Wang S, Zhang Z, Gao X, Chen Z, Xue $\mathrm{H}$ and Li G: Immunosuppressive effects of hypoxia-induced glioma exosomes through myeloid-derived suppressor cells via the miR-10a/Rora and miR-21/Pten Pathways. Oncogene 37: 4239-4259, 2018.

32. Luo Q, Cai Z, Tu J, Ling Y, Wang D and Cai Y: Total flavonoids from Smilax glabra Roxb blocks epithelial-mesenchymal transition and inhibits renal interstitial fibrosis by targeting miR-21/PTEN signaling. J Cell Biochem 120: 3861-3873, 2019.

33. Emini Veseli B, Perrotta P, De Meyer GRA, Roth L, Van der Donckt C, Martinet W and De Meyer GRY: Animal models of atherosclerosis. Eur J Pharmacol 816: 3-13, 2017.

34. Olvera Lopez E and Jan A: Cardiovascular Disease. In: editors. StatPearls. Treasure Island (FL): 2019. p.

35. Ma ZG, Kong CY, Song P, Zhang X, Yuan YP and Tang QZ: Geniposide protects against obesity-related cardiac injury through AMPKalpha- and Sirt1-Dependent Mechanisms. Oxid Med Cell Longev 2018: 6053727, 2018.

36. Zhang Z, Wang X, Zhang D, Liu Y and Li L: Geniposide-mediated protection against amyloid deposition and behavioral impairment correlates with downregulation of mTOR signaling and enhanced autophagy in a mouse model of Alzheimer's disease. Aging (Albany NY) 11: 536-548, 2019.

37. Liao P, Liu L, Wang B, Li W, Fang X and Guan S: Baicalin and geniposide attenuate atherosclerosis involving lipids regulation and immunoregulation in ApoE-/- mice. Eur J Pharmacol 740: 488-495 2014.

38. Liu L, Liao P, Wang B, Fang X, Li W and Guan S: Oral administration of baicalin and geniposide induces regression of atherosclerosis via inhibiting dendritic cells in ApoE-knockout mice. Int Immunopharmacol 20: 197-204, 2014.

39. Paone S, Baxter AA, Hulett MD and Poon IKH: Endothelial cell apoptosis and the role of endothelial cell-derived extracellular vesicles in the progression of atherosclerosis. Cell Mol Life Sci 76: 1093-1106, 2019.

40. Oyama Y,Bartman CM, Gile J and Eckle T: Circadian microRNAs in Cardioprotection. Curr Pharm Des 23: 3723-3730, 2017.

41. Yang Q, Yang K and Li A: microRNA-21 protects against ischemia-reperfusion and hypoxia-reperfusion-induced cardiocyte apoptosis via the phosphatase and tensin homolog/Akt-dependent mechanism. Mol Med Rep 9: 2213-2220, 2014.

42. Zhang JY, Ma J, Yu P, Tang GJ, Li CJ, Yu DM and Zhang QM: Reduced beta 2 glycoprotein I prevents high glucose-induced cell death in HUVECs through miR-21/PTEN. Am J Transl Res 9 : 3935-3949, 2017.
43. Nariman-Saleh-Fam Z, Vahed SZ, Aghaee-Bakhtiari SH, Daraei A, Saadatian Z, Kafil HS, Yousefi B, Eyvazi S, Khaheshi I, Parsa SA, et al: Expression pattern of miR-21, miR-25 and PTEN in peripheral blood mononuclear cells of patients with significant or insignificant coronary stenosis. Gene 698: 170-178, 2019.

44. Qiang Z, Meng L, Yi C, Yu L, Chen W and Sha W: Curcumin regulates the miR-21/PTEN/Akt pathway and acts in synergy with PD98059 to induce apoptosis of human gastric cancer MGC-803 cells. J Int Med Res 47: 1288-1297, 2019.

45. Zhang H, Feng X, Zhang M, Liu A, Tian L, Bo W, Wang H and $\mathrm{Hu}$ Y: Long non-coding RNA CASC2 upregulates PTEN to suppress pancreatic carcinoma cell metastasis by downregulating miR-21. Cancer Cell Int 19: 18, 2019.

46. Ma J and Ding Y: Geniposide suppresses growth, migration and invasion of MKN45 cells by down-regulation of lncRNA HULC. Exp Mol Pathol 105: 252-259, 2018.

47. Kattoor AJ, Pothineni NVK, Palagiri D and Mehta JL: Oxidative stress in atherosclerosis. Curr Atheroscler Rep 19: 42, 2017.

48. Khosravi M, Poursaleh A, Ghasempour G, Farhad S and Najafi M: The effects of oxidative stress on the development of atherosclerosis. Biol Chem 400: 711-732, 2019.

49. Lu W, Zhao Y, Kong Y, Zhang W, Ma W, Li W and Wang K: Geniposide prevents $\mathrm{H}_{2} \mathrm{O}_{2}$-induced oxidative damage in melanocytes by activating the PI3K-Akt signalling pathway. Clin Exp Dermatol 43: 667-674, 2018.

50. Liu W, Li G, Holscher C and Li L: Neuroprotective effects of geniposide on Alzheimer's disease pathology. Rev Neurosci 26: 371-383, 2015.

51. Shin D, Lee S, Huang YH, Lim HW, Lee Y, Jang K, Cho Y, Park SJ, Kim DD and Lim CJ: Protective properties of geniposide against UV-B-induced photooxidative stress in human dermal fibroblasts. Pharm Biol 56: 176-182, 2018.

52. Magenta A, Dellambra E, Ciarapica R and Capogrossi MC: Oxidative stress, microRNAs and cytosolic calcium homeostasis. Cell Calcium 60: 207-217, 2016.

53. Pereira-da-Silva T, Coutinho Cruz M, Carrusca C, Cruz Ferreira R, Napoleao P and Mota Carmo M: Circulating microRNA profiles in different arterial territories of stable atherosclerotic disease: A systematic review. Am J Cardiovasc Dis 8: 1-13, 2018

54. Fredman G and Tabas I: Boosting Inflammation Resolution in Atherosclerosis: The Next Frontier for Therapy. Am J Pathol 187: 1211-1221, 2017.

55. Wu MY, Li CJ, Hou MF and Chu PY: New Insights into the Role of Inflammation in the Pathogenesis of Atherosclerosis. Int J Mol Sci 18: pii: E2034, 2017:

56. Sheedy FJ: Turning 21: Induction of miR-21 as a key switch in the inflammatory response. Front Immunol 6: 19, 2015.

57. Yue S, Rao J, Zhu J, Busuttil RW, Kupiec-Weglinski JW, Lu L, Wang X and Zhai Y: Myeloid PTEN deficiency protects livers from ischemia reperfusion injury by facilitating M2 macrophage differentiation. J Immunol 192: 5343-5353, 2014.

(i) $\Theta$ This work is licensed under a Creative Commons Attribution-NonCommercial-NoDerivatives 4.0 International (CC BY-NC-ND 4.0) License. 